\title{
A Novel Bi-directional Series Parallel Resonant Converter for Power Factor Correction
}

\author{
Sivachidambaranathan.V \\ Research Scholar, Sathyabama University, \\ Chennai, India
}

\author{
Subhransu Sekhar Dash \\ Prof \& Head, SRM University, \\ Chennai, India
}

\begin{abstract}
Resonant converters are very attractive in practice because they have high efficiency, small size, light weight, fast dynamic response, low component stresses and low noise. One of the relatively new resonant DC-DC converters is a Series-Parallel Resonant Converter (SPRC) also called an LCC converter. Under constant frequency, the filter designs are simplified and utilization of magnetic components is improved. The LCC-SPRC takes on the desirable characteristics of the pure series and the pure parallel converter, thus removing the main disadvantages. The use of soft-switching techniques alleviates switching loss problems and allows a significant increase in the converter switching frequency. In the present work Bi-directional Series Parallel Resonant Converter are designed and the simulation results are presented.
\end{abstract}

\section{Keywords}

High frequency converter; Isolated LCC converter; ZVS bidirectional converter.

\section{INTRODUCTION}

In recent years, the series-parallel resonant LLC converter becomes more and more popular in isolated DC-DC applications due to its high power density, high efficiency and long hold-up time capability [1]. With the development of power conversion technology, power density and efficiency of the converter has become the major challenge [2]. In recent decades, research on AC-DC converters with power factor correction and low Total Harmonic Distortion is consistently enjoying increasing interests. As the industry interests and applications of these converters increase [3]. Over the last decade great performance improvement has been observed in hard-switching DC/DC converters. However, it seems the limits of this technique have been reached. Switching frequencies of few kilohertz for high power applications are possible. For further increase of switching frequency up to $100 \mathrm{KHz}$ and reduction of electro magnetic interference, resonant converters have to be applied [4].

The switching losses in the power switches the rectifier diodes are greatly reduced so that the operation at high frequencies is possible with increased efficiency and reliability [5]. Lowvoltage MOSFETs have low on-resistances, resulting in low conduction losses and yielding high efficiency was given by Marian K. Kazi Mierczuk [6]. In MOSFETs, because of high drain-source capacitance, Zero Voltage Switching (ZVS) is more effective than Zero Current Switching (ZCS). On the other hand, in IGBTs, because of the tail-current characteristic at turnoff, ZCS is more effective than ZVS. To apply IGBTs for ZVS cases, an additional lossless turn-off snubber should be added in parallel with IGBTs was given by Eung-Ho Kim and Bong-Hwan Kwon [7]. In the present work MOSFETS are used as switches.
The advantages of Series Resonant Converter (SRC) topology are load independent output voltage operation excellent efficiency from full load to reduced load and inherent short circuit capability. The disadvantages of SRC are

a. The output dc filter capacitor carries high ripple current this posses a problem in controlling the output ripple voltage over the dc output.

b. The switching frequency varies directly with the load resulting in a poor cross regulation in multi output power supply.

c. It cannot operate at zero load.

The advantages of Parallel Resonant Converter (PRC) are that the output DC filter capacitor does not carry high ripple current and also it exhibits good voltage regulation. The disadvantages of PRC are the higher device current results in reduced efficiency. Since the device current does not decrease with load, the efficiency drops with a decrease in load.

It is possible to retain the advantages of SRC and PRC, while eliminating / minimizing their disadvantages. This is achieved by the addition of third resonant element that modifies input output characteristics substantially resulting in load independent operation.

Secondary batteries are widely used in the application of residential, industrial and commercial energy storage systems to store electricity and supply the load for various types of electronic equipment was explained by Ying-Chun Chuang et al [8]. Resonant converters topology has been used for telecommunications and aerospace applications and it has been recently proposed for electric vehicles was given by Ricardo Barrero [9]. Resonant inverters are connected to a High-Frequency AC (HFAC) bus, where power is delivered to different locations for points-of-use power management. HFAC power distribution systems have been widely investigated and used for applications such as personal computers, space stations, aerospace and telecommunications [10].

A High Power LED Driver with Class D ZVS Series Resonant Converter was given by Pakpoom Chansri et al.[11]. Series Parallel Resonant Converter for Electrical Discharge Machining Power Supply was given by Aparna S and Kasirathi N [12]. Implementation of series parallel resonant converter with series parallel transformer was given by Lin B.R. and Wu S.F [13]. Series Resonant Converter with Series-Parallel transformers for high input voltage applications given by Chang-Hung Chien et al [14].

\section{SERIES PARALLEL INVERTER}

A full bridge series parallel resonant inverter is used for the investigation is presented in Fig 1. The circuit consists of full bridge MOSFET inverter. The resonant inductor $L_{r}$ and 
capacitor $\mathrm{C}_{\mathrm{s}}$ and $\mathrm{C}_{\mathrm{r}}$. The resonant capacitor $\mathrm{C}_{\mathrm{s}}$ is in series with resonant inductor $\mathrm{L}_{\mathrm{r}}$ and the load, $\mathrm{C}_{\mathrm{r}}$ is in parallel with the load and they form a Series Parallel LC circuit. From this configuration, the resonant tank and the load circuit act as a voltage divider. By changing the frequency of the input voltage, the impedance of the tank will change. This impedance will drive the input voltage with the load.

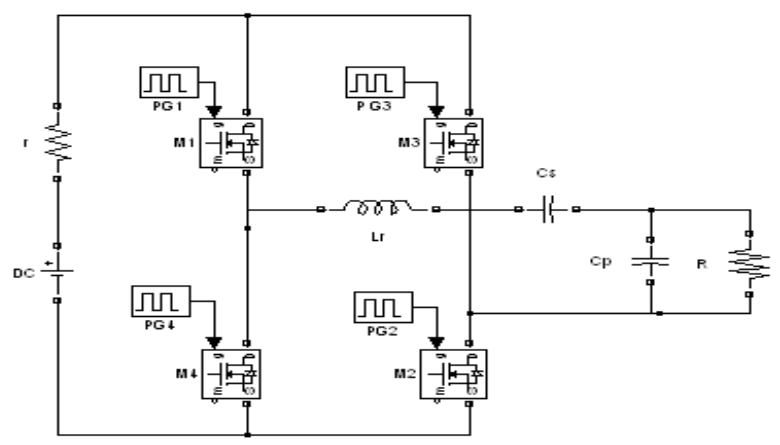

Fig 1: Full bridge Basic series parallel inverter

\section{CIRCUIT DESCRIPTION AND}

\section{WORKING}

Fig. 2 shows the simulation circuit for full bridge series parallel resonant converter. The circuit consists of a AC input source, full bridge diode rectifier, filter circuit, full bridge MOSFET inverter having a high frequency (HF) resonant circuit. A HF transformer provides voltage transformation and isolation between the source and the load. A load can be connected to the high frequency link circuit with secondary full bridge rectifier and smoothing filter circuits.

The input AC source is rectified by full bridge diode rectifier. The DC voltage is filtered by using capacitor. The DC voltage is inverted by high frequency MOSFET full bridge inverter. Pulse generators are connected to the gate of the MOSFET. When $M_{1} M_{2}$ conducts, $M_{3} M_{4}$ should be in off state and vice versa, to avoid short circuit.

Output of the inverter is connected to primary of the transformer through resonant inductor $\mathrm{L}_{\mathrm{r}}$ and capacitor $\mathrm{C}_{\mathrm{s}}$ in series. The secondary of the transformer is then connected to MOSFET full bridge rectifier. The resonant capacitor $C_{p}$ is connected in parallel with secondary instead of primary. The LC tank circuit is called as resonant circuit.

The resonant link circuit is driven with either square waves of voltage or current in the inverter. The voltage or current in the resonant components becomes minimum at the resonant frequency and by altering the frequency around the resonant point, the voltage on the resonant components can be adjusted to any desired value. By rectifying the voltage across the secondary of the transformer, a dc voltage is obtained which is filtered to achieve smooth DC. Scopes are connected to display the input current and voltage, gate pulses, output voltage, current, etc.

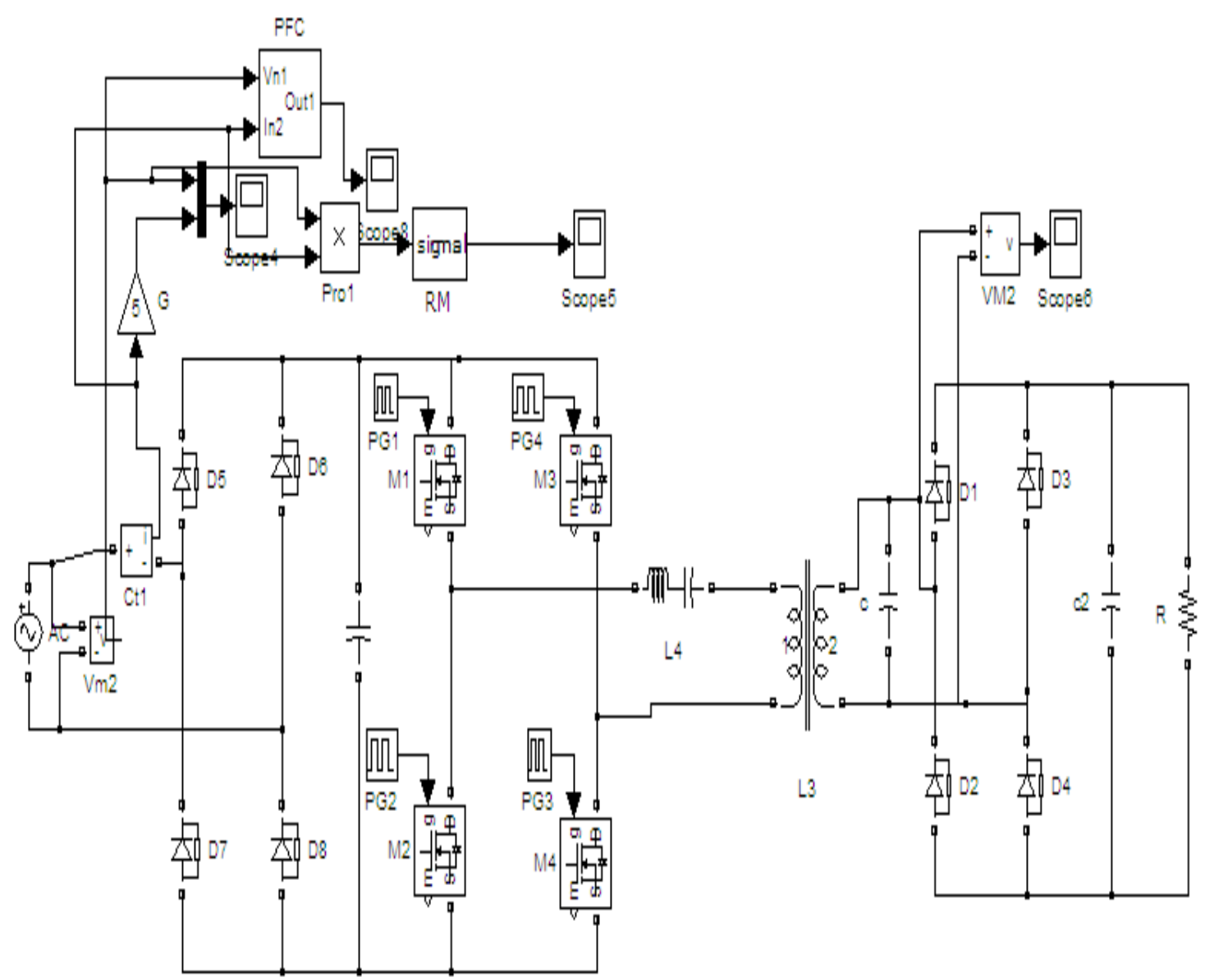

Fig 2: Simulation circuit for series parallel resonant converter 


\section{SIMULATION RESULTS}

The simulation of full bridge series resonant converter is done using Matlab and results are presented here. Fig. 3 shows the gate pulse and Drain source voltage waveforms for MOSFETs $\mathrm{M}_{1}$ and $\mathrm{M}_{4}$. Fig. 4 shows the gate pulse and Drain source voltage waveforms for MOSFETs $\mathrm{M}_{2}$ and $\mathrm{M}_{3}$. From the wave form it is clear that when the pulse to the MOSFET is high, the output is low. (ie) the switch is in conduction state. When the device conducts the voltage across the device is very less.

The output of series resonant inverter, primary side voltage and current waveforms are shown in Fig 5. Secondary side voltage and current waveforms are shown in Fig.6. The sinusoidal current waveforms are obtained at the output of LC circuit. The LLC resonant inverter reduces harmonics of the transformer.
DC output voltage and current waveforms are shown in Fig.7 and Fig. 8 respectively. DC output voltage across the load is found to be $12 \mathrm{~V}$. It has been observed that, constant output voltage and current waveforms are obtained for the series parallel resonant converter.

Input voltage and current waveforms are shown in Fig.9. From the wave form it is clear that when the voltage crosses zero, the current also crosses zero point. The voltage is in phase with current wave form. This results in improved power factor.

The power factor waveform is shown in Fig. 10. From this waveform is clear that the power factor maintains constant value and it is found to be nearly 0.96 .

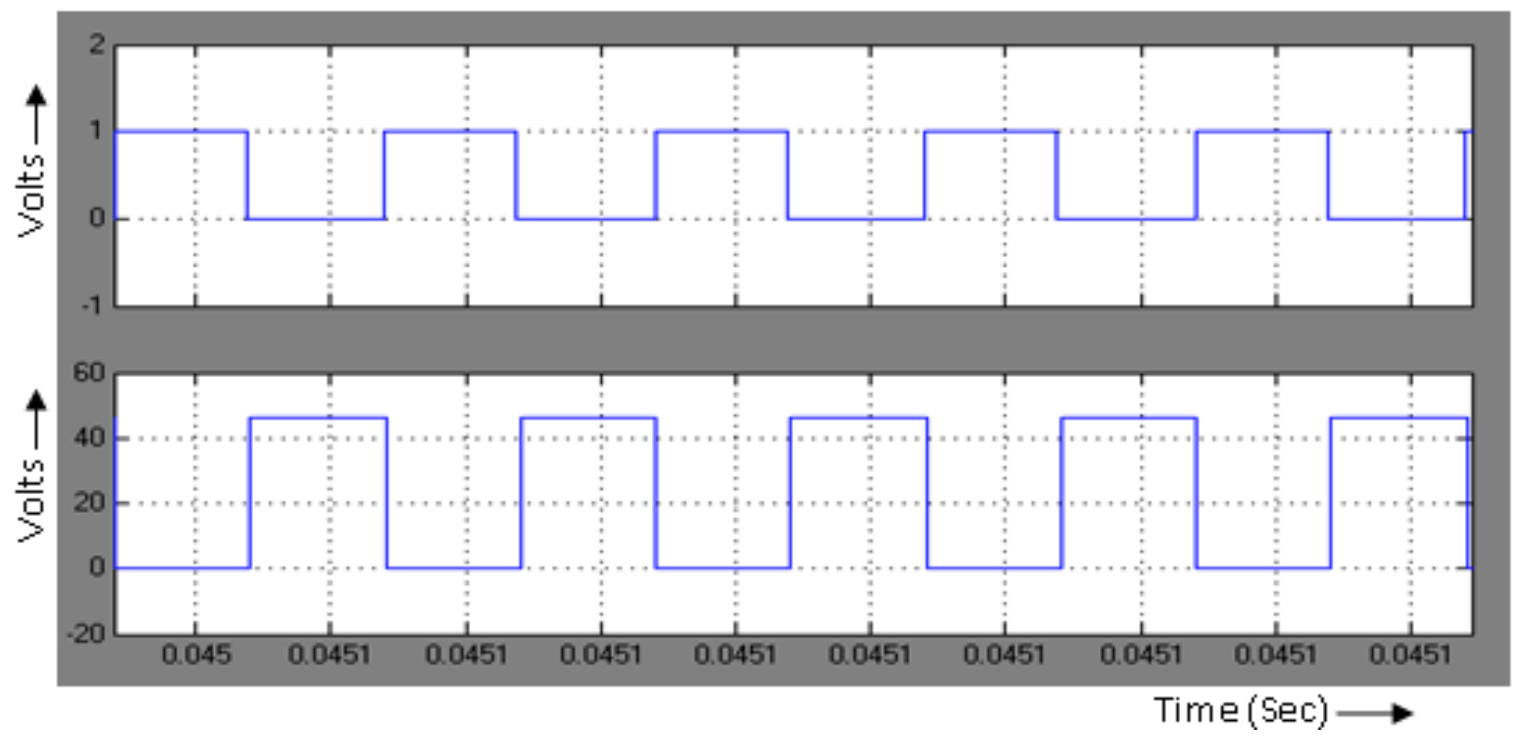

Fig 3: Gate pulse and drain source voltage across MOSFET $M_{1}$ and $M_{4}$

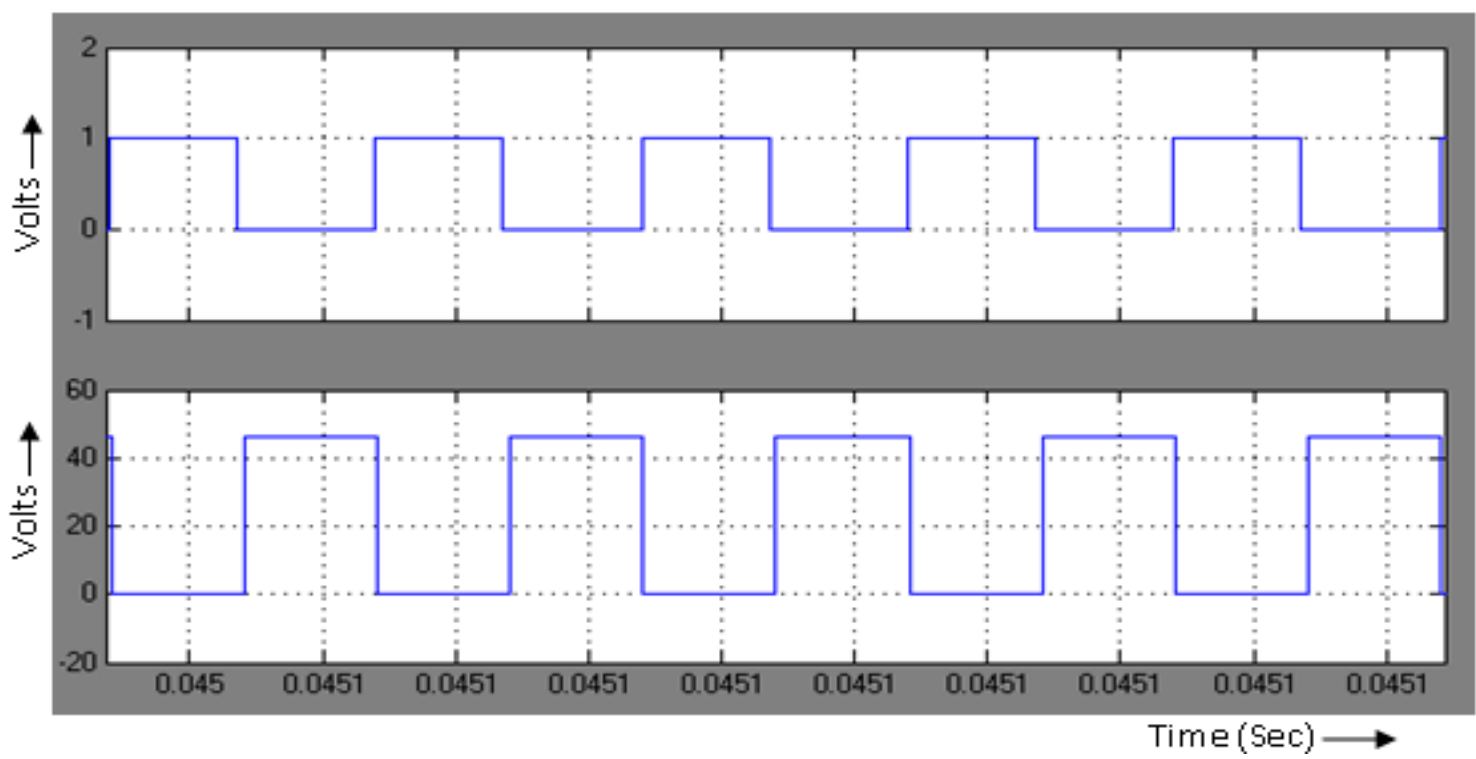

Fig 4: Gate pulse and drain source voltage across MOSFET $M_{2}$ and $M_{3}$ 


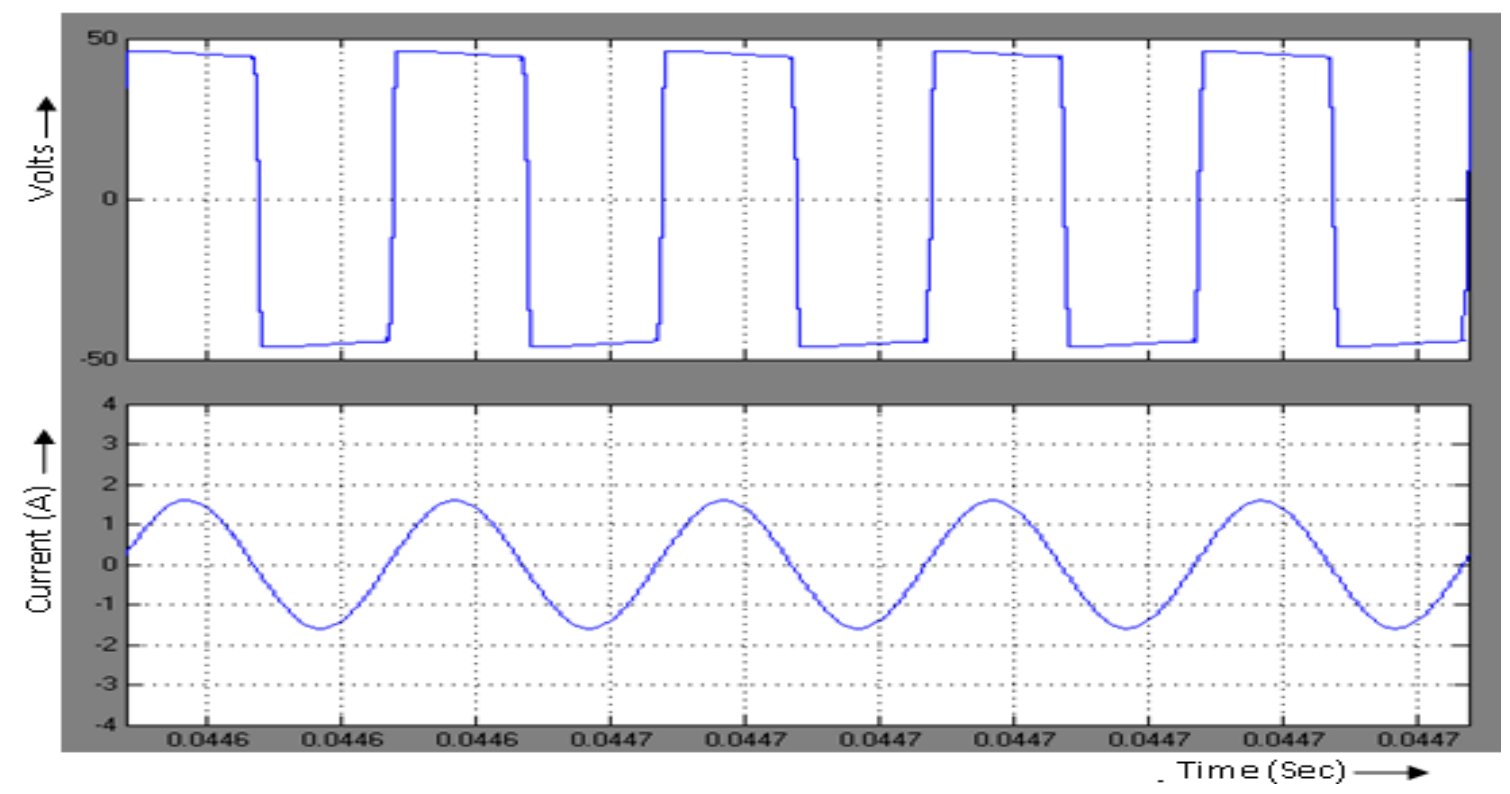

Fig 5: Transformer primary voltage \& current

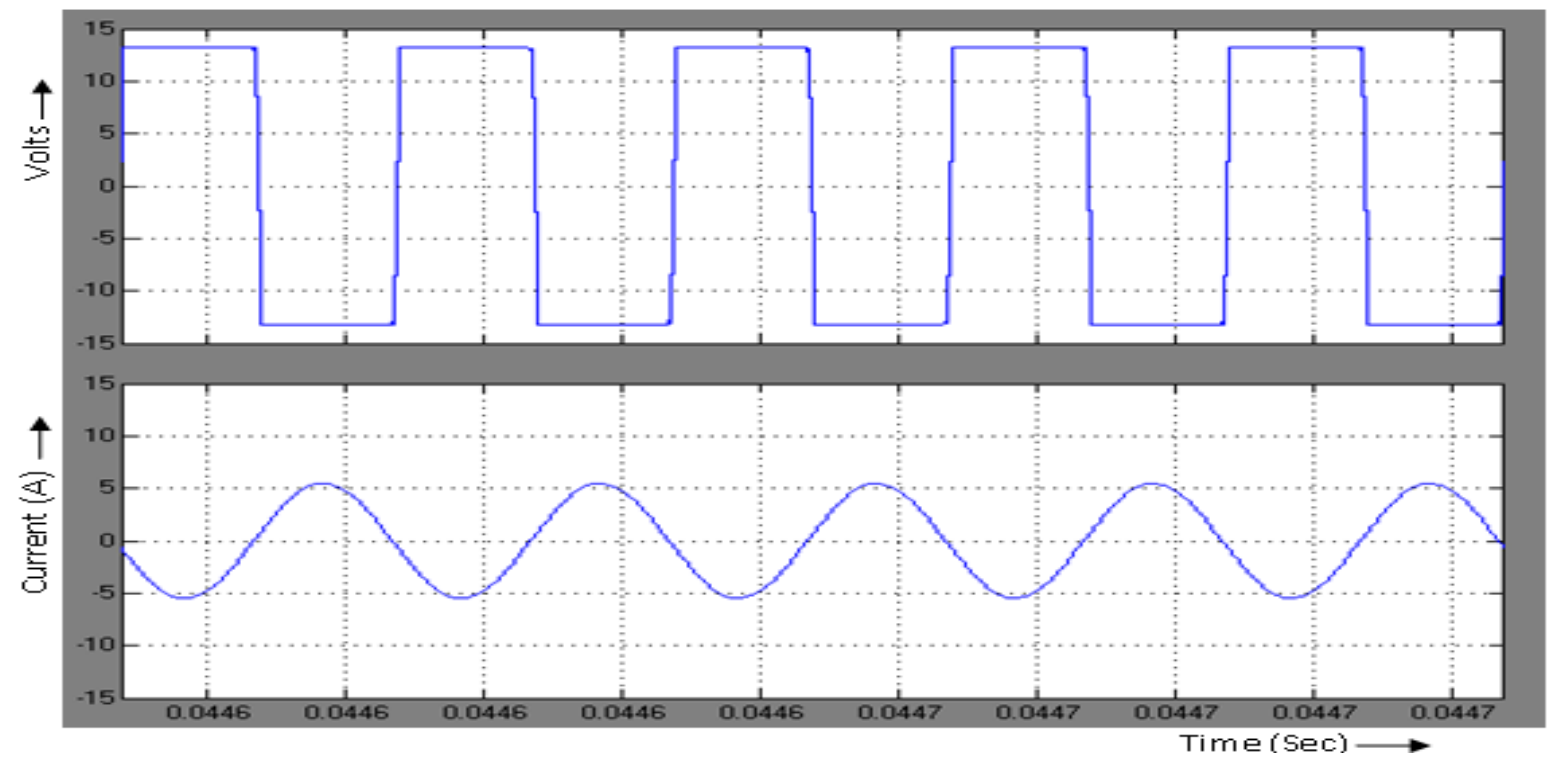

Fig 6: Transformer secondary voltage \& current

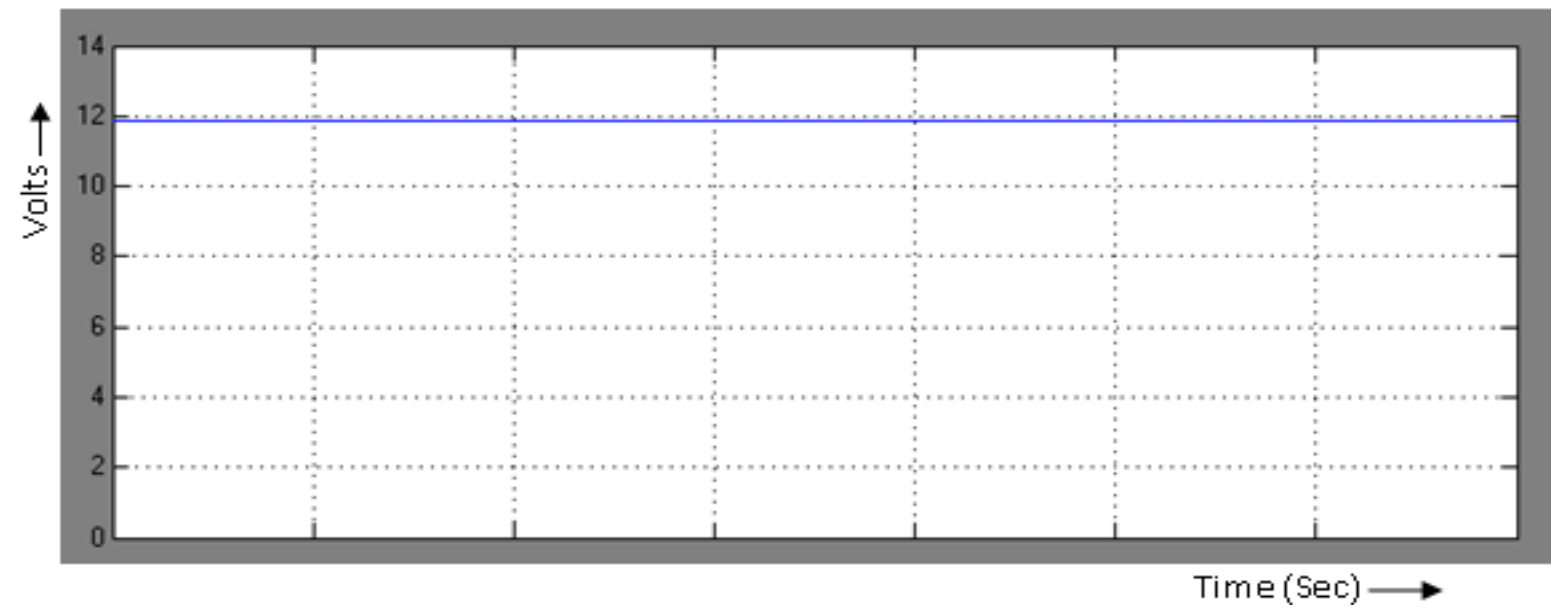

Fig 7: Output voltage 


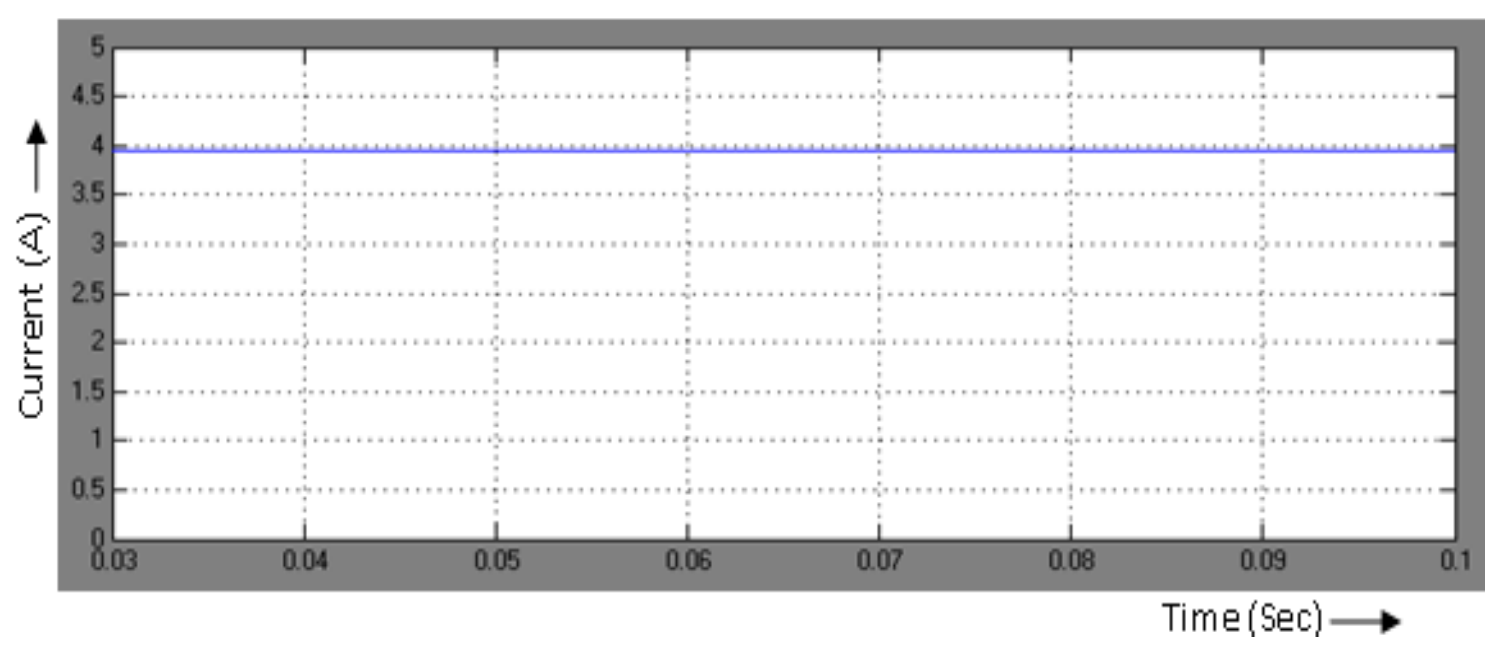

Fig 8: Output current

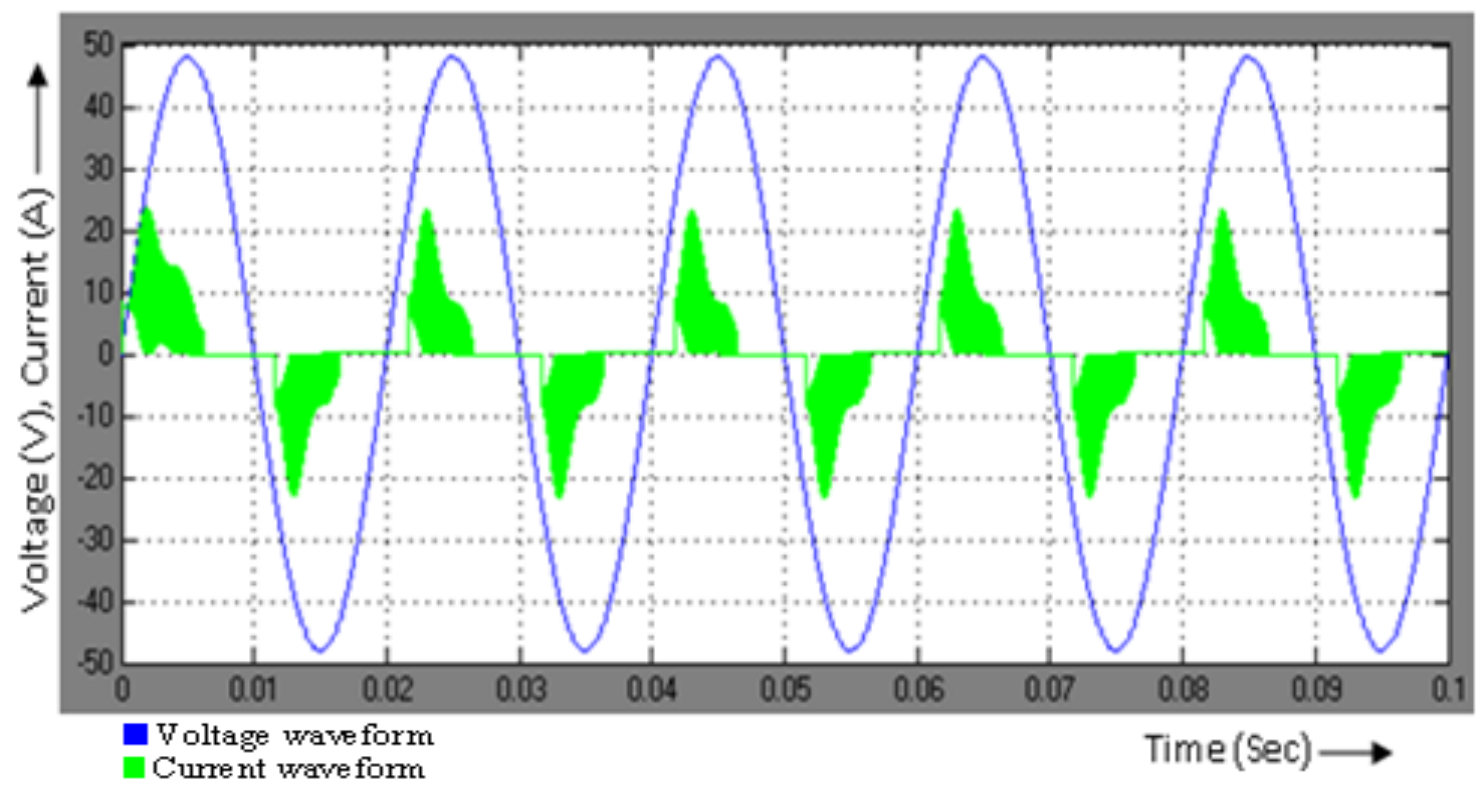

Fig 9: Input Voltage and Current

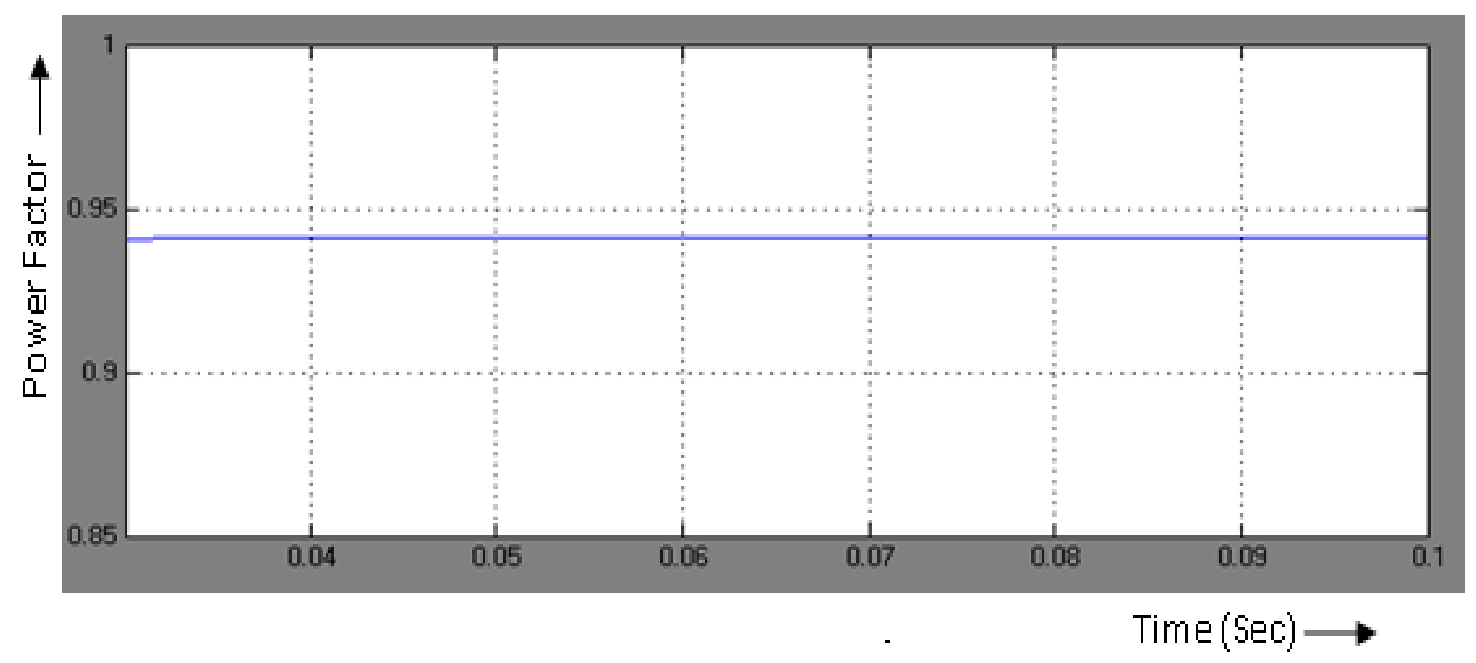

Fig 10: Power Factor 


\section{CONCLUSION}

Full bridge series parallel resonant converter is simulated using Matlab simulink and the results are presented. The results shows that the output voltage wave form is smooth and ripple less. Also the input voltage and current waveform is in phase with each other. The voltage and current cross zero point at the same time. The power factor is found to be nearly unity. There by reducing the switching loss and voltage stress on the switch the efficiency is improved. The series parallel resonant converter has advantages like high power density, reduced EMI, reduced switching losses and stresses. This converter is suitable for low voltage DC applications such as to operate a car radio, mobile phones, $12 / 3 \mathrm{~V} \mathrm{DC}$ for personal CD players, CPU Chips, etc.

\section{REFERENCES}

[1] Xinke Wu, Guichao Hua, Junming Zhang and Zhaoming Qian, "A New Current Driven Synchronous Rectifier for Series-Parallel Resonant (LLC) DC-DC Converter", IEEE Transactions on Industrial Electronics, Vol.58, Issue I, 2010 pp $289-297$

[2] Moon-Young Kim, Bong-Chul Kim, Ki-Bum Park and Gun-Woo Moon, "LLC Series Resonant Converter with Auxiliary Hold-Up Time Compensation Circuit", 8th IEEE International Conference on Power Electronics ECCE, May 30-June 3, 2011, pp 628 - 633

[3] M.M.A. Rahman, "Single-phase single-stage 3-Level AC-to-DC series resonant converter", IEEE Inter national Conference on Electro / Information Tehnology, 2007 , pp, 569, 573.

[4] Antoni Dmowsk, Rafal Bugyi and Piotr Szewczyk. "A novel series-resonant dc/dc converter with full control of output voltage at no-load condition computer simulation based design aspects", Industry Applications Society Annual Meeting, IEEE Conference, Vol.1, 1992 pp 924 -928 .

[5] Marian K. Kazimierczuk and Manikantan K. Jutty, "Fixed-Frequency Phase-Controlled Full-Bridge Resonant Converter With a Series Load" IEEE Trans. on Power Electronics, Vol. 10, NO. 1,pp 10-18, January1995

[6] Marian K. Kazi Mierczuk, Nandakumar, Thirunarayan and Shan Wang, "Analysis of Series-Parallel Resonant Converter", IEEE Trans. on Aerospace and Electronics systems, Vol 29, No. 1, pp 88-99, JANUARY 1993.

[7] Eung-Ho Kim and Bong-Hwan Kwon, "Zero-Voltageand Zero-Current-Switching Full-Bridge Converter With Secondary Resonance", IEEE Trans. on Industrial Electronics, Vol. 57, NO. 3, March 2010 pp1017-1025

[8] Ying-Chun Chuang, Yu-Lung Ke, Hung-Shiang Chuang and Yu-Min Chen, "Analysis and Implementation of Half-Bridge Series-Parallel Resonant Converter for Battery Chargers", IEEE Trans on Industrial Appln., VOL. 47, NO. 1, 2011, pp $258-270$.
[9] Ricardo Barrero, Joeri Van Mierlo \& Philippe Lataire, "Design of Bi-directional Series Resonant Converter as Peak Power Unit in Hybrid Electric Vehicles", IEEE international conference on Industrial Technology (ICIT), 2010, pp 1102 - 1107

[10] Zhongming Ye, John C. W. Lam, Praveen K. Jain, and Paresh C. Sen, "A Robust One-Cycle Controlled FullBridge Series-Parallel Resonant Inverter for a HighFrequency AC (HFAC) Distribution System", IEEE Trans on Power Electronics, VOL. 22, NO. 6, Nov 2007, pp 2331-2343

[11] Pakpoom Chansri, Nongnuch Noicharoen and Kritsada Phetphoi, "A High Power LED Driver with Class D ZVS Series Resonant Converter", International Conference on Electrical, Control and Computer Engineering Pahang, Malaysia, June 21-22, 2011pp 457-460.

[12] Aparna, S. Kasirathi, N, "Series Parallel Resonant Converter for Electrical Discharge Machining Power Supply", IEEE International conference on Electrical Energy Systems, 2011, pp 28-33.

[13] Lin, B.R.; Wu, S.F, "Implementation of series parallel resonant converter with series parallel transformer", IET Journals, Vol 4, Issure 8, pp 919-926.

[14] Chang-Hung Chien; Yeong-Her Wang; Bor-Ren Lin (2011),"Series Resonant Converter with Series-Parallel transformers for high input voltage applications", IEEE International conference, TENCON 2011, PP 873-877.

\section{AUTHOR'S PROFILE}

V.Sivachidambaranathan has completed Diploma in Electrical and Electronics Engineering, DOTE, Chennai in 1994, AMIE degree in Electrical Engineering from the Institution of Engineers (INDIA), Section A and Section B in 1997 and 2002, and M.E. degree in Power Electronics and Industrial Drives from Sathyabama Institute of Science and Technology, Chennai in 2005. He is a life member of Indian Society for Technical Education. Presently he is pursuing $\mathrm{Ph} . \mathrm{D}$. programme at Sathyabama University, Chennai. He has published 25 papers in various Journals and Conferences. His research interests include DC - DC converters and power factor correction converters

Dr. S.S.Dash is presently working as a Professor and Head of the Department of Electrical and Electronics Engineering, SRM Engineering College, SRM University, Chennai. He has completed his graduation in Electrical Engineering in the year 1994. He got his M.E. in Power Systems Engineering from University College of Engineering, Burla, Orissa in 1996 and obtained his Ph.D degree from College of Engineering, Guindy, Anna University, Chennai in the year of 2004. He was formerly a faculty member of Anna University, College of Engineering, Guindy, Chennai. He has published more than 50 papers in International Journal and Conferences. His research areas are Modelling of FACTS Controller, Power Electronics and Drives, Power System Stability and Artificial Intelligence. He is a life member of Indian Society for Technical Education and Institution of Engineers, India. 